\title{
Memory Impairment Allied to Temporal Lobe Epilepsy and its Deterioration by Phenytoin: A Highlight on Ameliorative Effects of Levetiracetam in Mouse Model
}

\author{
Asher John Mohan ${ }^{1} \quad$ Kamsagara Linganna Krishna ${ }^{1}$ \\ ${ }^{1}$ Department of Pharmacology, JSS College of Pharmacy, \\ JSS Academy of Higher Education and Research, Mysore, \\ Karnataka, India
}

\begin{abstract}
Address for correspondence Kamsagara Linganna Krishna, M. Pharm, PhD, Department of Pharmacology, JSS College of Pharmacy, JSS Academy of Higher Education and Research, Mysore 570015, Karnataka, India (e-mail: klkrishna@jssuni.edu.in).
\end{abstract}

Int J Epilepsy 2018;5:19-27

\begin{abstract}
Keywords

- pilocarpine

- phenytoin

- levetiracetam

- antiepileptic drugs

Background/Objectives Memory impairment (MI) and epilepsy go hand in hand, mainly in conditions of temporal lobe epilepsy (TLE). This disease comorbidity has been reported to worsen upon treatment. Hence this study aims to evaluate the extent of aggravating effect of phenytoin (PHT) at normal and reduced doses on MI associated with TLE and additionally assesses the protective effect of levetiracetam (LEV) on these adverse effects.

Methods Swiss albino mice of either sex $(n=36)$ were used for this study in which seizures were induced by intraperitoneal administration of pilocarpine $(300 \mathrm{mg} / \mathrm{kg}$ i.p.) followed by evaluation of antiepileptic activity by technique of Racine's scale for convulsive scores. Errors (a factor denoting MI) were assessed using radial arm maze. Finally brain biochemical measures of acetylcholinesterase and glutamate along with cresyl violet staining and estimation of total neuronal number of the hippocampus were performed.

Results Exacerbation of MI by PHT was observed, where the extent of MI was found to be lesser in the reduced dose approach (PHTR: $28.50 \pm 1.03 ; p \leq 0.05$ ). However, this tactic in dose reduction was interfered with the antiepileptic potential of the drug. Attenuation of MI upon combining with LEV, without an interference in the principal treatment, was observed equally in the behavioral and brain aspects of the study (PHTN + LEV: $1.33 \pm 0.33$ and PHTR + LEV: $1.00 \pm 0.17 ; p \leq 0.05)$.

Conclusions The promising effects of $L E V$ could thus aid in proposing a new management remedy for TLE to minimize the adverse effect associated with it.
\end{abstract}

\section{Introduction}

Epilepsy resembles a neurodegenerative disorder, in which memory impairment (MI) is a common and undesirable factor. ${ }^{1}$ This is distinctively an observation found in cases of patients suffering from temporal lobe epilepsy (TLE)-a form of status epilepticus (SE) that is a life-threatening situation characterized by an epileptic seizure greater than 5 minutes or more than one seizure within a 5-minute period. ${ }^{2,3}$
Because the mainstay of treatment is the administration of antiepileptic drugs (AEDs) intended for the disease, reports of the same to have a negative impact on memory are not desired or accepted. ${ }^{4}$ Therefore, a treatment therapy for epilepsy, which is devoid of worsening cases of MI, is a necessity in today's scenario.

The pilocarpine model of SE is one of the well-established animal models for SE and shares many of the characteristics of human TLE. It is reported that pilocarpine (muscarinic 
cholinergic agonist) could induce robust limbic seizures when systemically administered to mice. ${ }^{5,6}$ Here phenytoin (PHT) is elected as the AED under evaluation, which has been approved and widely used till date as a first-line agent for the treatment of TLE, with outcomes to support its worsening states on the condition of memory. ${ }^{7.8}$ Because a variety of racetams (drugs sharing a pyrrolidine ring) have been commonly used as memory enhancers, the selection of LEV was based on the information that it additionally functions as an adjunct antiepileptic in the management of partial seizures $^{9,10}$ Other studies involving reports of LEV to have positive effects on cognition in cases of Tourette's syndrome and Alzheimer's disease were taken into consideration. ${ }^{11,12}$ An alternative rationale and benefit for the selection of LEV is its pharmacokinetic parameters that include faster absorption, negligible binding to plasma proteins, lack of enzyme induction, absence of interactions with other drugs, and restricted metabolism outside the liver. ${ }^{13}$

Therefore, this study aims at evaluating the effect of the chosen AED on MI associated with TLE (the authors have taken mouse model of TLE as a continuation study based on the previous study involving generalized seizures and preferred when compared with other models of epilepsy due to its feasibility and ease of operation) at normal and reduced doses (not less than its effective dose) upon combination with LEV using a mouse model.

\section{Methods}

\section{Animals}

Albino mice ( $n=36$ ) of either sex weighing 30 to $35 \mathrm{~g}$ were procured from the Central Animal House Facility of JSS Medical College, Mysore (CPCSEA 261/PO/ReBi/2000/CPCSEA, date: October 16, 2015-October 15, 2018). They were housed in polypropylene cages (mice were separated in cages based on their sex) with free access to food and water, at an ambient temperature $26^{\circ} \mathrm{C}$, humidity 50 to $60 \%$, and $12: 12$ light/ dark cycle. All efforts were made to minimize animal suffering, and chronic animal protocols were designed to reduce the number of animals used. Experiment protocols were performed in accordance with the approval of institutional animal ethics committee (IAEC) of JSSCP Mysore (proposal number 162/2014).

\section{Drugs, Chemicals, and Materials}

Phenytoin (normal $24 \mathrm{mg} / \mathrm{kg}$ and reduced $12 \mathrm{mg} / \mathrm{kg}$ body weight, p.o.) and LEV (25 mg/kg body weight, i.p.) required for the study were procured from Shivari Pharmaceuticals, Mysore, Karnataka, India. The doses were selected with slight variation based on their effectiveness as an antiepileptic and their toxic profile from the available literature. ${ }^{14,15}$ Pilocarpine $\mathrm{HCl}(300 \mathrm{mg} / \mathrm{kg}$ body weight, i.p.) from Sigma Aldrich was used to produce repetitive limbic seizures. Laboratory-made radial arm maze (RAM) was used in determining MI activity and Sony Handycam was used to record the arm preference and errors. Acetylthiocholine iodide, cage hydrate powder of glutamate and Whatman number 1 chromatography paper (Sigma Aldrich), butanol, acetic acid, ninhydrin, and cupric sulfate of analytical grade were used, provided by the JSS College of Pharmacy, Mysore, Karnataka, India. Brain studies involving histopathological staining and total neuronal number were performed by the Medall Clumax Diagnostic, Mysore, Karnataka.

\section{Pilocarpine Model of Status Epilepticus}

In this model, systemic injection of the pilocarpine induces SE, likely through activation of M1 muscarinic receptors, followed by a seizure-free latent period and eventually the appearance of recurrent seizures that continue for the rest of the animal's life. By monitoring the behavioral severity of each seizure, scores on a standard $0-5$ Racine scale were given. ${ }^{16}$

The animals were treated as per the schedule ( - Table 1 ) for 64 days (this period of study was developed as acute administration of PHT could not provoke worsening in conditions of MI when observed by hippocampal staining although behavioral alterations were present). Anticonvulsant potential of PHTN (24 mg/kg p.o.) and PHTR (12 mg/kg p.o.) in absence/ presence of LEV (25 mg/kg p.o.) was assessed every seventh day for a period of 64 days. Convulsions were induced by intraperitoneal administration of pilocarpine $300 \mathrm{mg} / \mathrm{kg}$ on every sixth day. Seizures in control animals were controlled by the administration of diazepam $5 \mathrm{mg} / \mathrm{kg}$. LEV as well as PHT was given orally 2 and 1 hour, respectively, before induction of convulsions. Convulsive scores were finally given (based on Racine's scale for seizures) as follows: 0 : no response, 1 : hypoactivity, 2: monoclonic jerks of the head and head bobbing, 3: bilateral activity of the whole body, 4: rearing of limbs, and 5: generalized tonic-clonic activity and loss of posture. ${ }^{17}$

\section{Memory Impairment Activity of Phenytoin by Radial Arm Maze}

The animals were divided into different groups as shown in Table 1, and MI activity was evaluated every week for a period of 64 days. Each animal was trained prior to the start of experiment on a daily basis for a period of 7 days in the maze to collect the food pellets. The maze was kept well illuminated. A modification of rewards by food pellets were replaced by application of butter in the inner areas of the escape box. This was done to help the animal in finding the escape box with the aid of olfactory senses. Once trained, the process of application of butter was excluded. During the test, mice were fed once a day and their body weights were maintained at $85 \%$ of their free feeding weight to motivate the animal to run the maze. The session was terminated after 120 seconds, and the animal had to find the escape box with a minimum number of errors. ${ }^{18}$

\section{Estimation of Brain Acetylcholinesterase Levels}

The reagents used were as per - Table 2. Mice, after 64 days, were euthanized using carbon dioxide method and brains were removed quickly and placed in ice-cold saline. Frontal cortex was quickly dissected out on a petri dish chilled on crushed ice. The tissues were weighed and homogenized in $0.1 \mathrm{M}$ phosphate buffer ( $\mathrm{pH} \mathrm{8.0)}$. A $0.4 \mathrm{~mL}$ aliquot of the homogenate was added to a cuvette containing $2.6 \mathrm{~mL}$ phosphate buffer ( $0.1 \mathrm{M}, \mathrm{pH} 8.0)$ and $100 \mu \mathrm{L}$ of DTNB. The contents of the cuvette were mixed thoroughly by bubbling air, and 
Table 1 Treatment schedule

\begin{tabular}{|c|c|c|c|}
\hline Group & $n$ & Treatment & Evaluation \\
\hline Normal & 6 & $\begin{array}{l}0.5 \% \text { CMC (vehicle) was administered orally for } 64 \\
\text { days. }\end{array}$ & $\begin{array}{l}\text { MI activity was on days } 8,15,22,29,36 \text {, } \\
43,50,57 \text {, and } 64 \text { for a total period of } \\
64 \text { days }\end{array}$ \\
\hline Control & 6 & $\begin{array}{l}\text { Vehicle p.o. every day + convulsions induced by pilo- } \\
\text { carpine i.p. every } 7 \text { th day for a period of } 64 \text { days. After } \\
\text { observation of all Racine stages, seizures were termi- } \\
\text { nated by administration of diazepam } 5 \mathrm{mg} / \mathrm{kg} \text { i.p. }\end{array}$ & $\begin{array}{l}\text { Convulsive scores (antiepileptic activity) } \\
\text { on every } 7 \text { th day followed by Error scores } \\
\text { of RAM (MI activity) on days } 8,15,22 \text {, } \\
29,36,43,50,57 \text {, and } 64 \text { for a total } \\
\text { period of } 64 \text { days }\end{array}$ \\
\hline PHTN & 6 & $\begin{array}{l}\text { PHTN p.o. every day + convulsions induced by pilocar- } \\
\text { pine i.p. every 7th day for a period of } 64 \text { days. }\end{array}$ & Same as above \\
\hline PHTR & 6 & $\begin{array}{l}\text { PHTR p.o. every day + convulsions induced by pilocar- } \\
\text { pine i.p. every } 7 \text { th day for a period of } 64 \text { days. }\end{array}$ & Same as above \\
\hline PHTN + LEV & 6 & $\begin{array}{l}\text { PHTN p.o. and LEV i.p. every day } 2 \mathrm{~h} \text { and } 1 \mathrm{~h} \text { prior to } \\
\text { convulsions induced by pilocarpine i.p. every } 7 \text { th day } \\
\text { for a period of } 64 \text { days. }\end{array}$ & Same as above \\
\hline PHTR + LEV & 6 & $\begin{array}{l}\text { PHTR and LEV p.o. every day } 2 \mathrm{~h} \text { and } 1 \mathrm{~h} \text { prior to con- } \\
\text { vulsions induced by pilocarpine i.p. every } 7 \text { th day for a } \\
\text { period of } 64 \text { days. }\end{array}$ & Same as above \\
\hline
\end{tabular}

Abbreviations: CMC, carboxymethyl cellulose; LEV, levetiracetam $25 \mathrm{mg} / \mathrm{kg}$ body weight; MI, memory impairment; PHTN, phenytoin normal dose (24 mg/kg body weight); PHTR, phenytoin reduced dose (12 mg/kg body weight).

Exception: For groups PHTN + LEV and PHTR + LEV, pilocarpine was administered on every seventh day for a period of 14 days prior to the start of treatment. This caused disruption in the learning curve that aided the reversal or diminishing of the effect of LEV on MI.

Table 2 Reagent composition

\begin{tabular}{|l|l|l|}
\hline Reagents & Sample $(\mathrm{mL})$ & Blank $(\mathrm{mL})$ \\
\hline Phosphate buffer solution & 2.6 & 2.7 \\
\hline Supernatant & 0.4 & 0.4 \\
\hline DTNB & 0.1 & - \\
\hline
\end{tabular}

absorbance was measured at $412 \mathrm{~nm}$ in a spectrophotometer. When absorbance reached a stable value, it was recorded as the basal reading. Substrate, that is, acetylthiocholine $(20 \mu \mathrm{L})$, was added and change in absorbance was recorded. Change in the absorbance per minute was thus determined. . $^{190}$

$$
\text { The enzyme levels }=\Delta A^{*} V t / € b^{*} V s^{*} X
$$

where $\Delta \mathrm{A}$ is change in absorbance, Vt is total volume (3.1), $€$ is $13610^{*} 104$, b is path length $(1 \mathrm{~cm})$, Vs is sample volume $(0.4 \mathrm{~mL})$, and $\mathrm{X}$ is $\mathrm{mg}$ protein of brain tissue.

\section{Estimation of Brain Glutamate Levels \\ Preparation of Reagents}

Solvent: butanol:acetic acid:water (12:3:5): $60 \mathrm{~mL}$ of butanol, $15 \mathrm{~mL}$ of acetic acid, and $25 \mathrm{~mL}$ distilled water was added; $0.25 \%$ ninhydrin: $200 \mathrm{mg}$ of ninhydrin was dissolved in $99 \mathrm{~mL}$ of acetone. To this solution, $1 \mathrm{~mL}$ of pyridine was added, and 0.005\% CuSO4 solution: $5 \mathrm{mg}$ of cupric sulfate was dissolved in $10 \mathrm{~mL} \mathrm{75 \%} \mathrm{alcohol.}$

\section{Standards}

Solvent: $2 \mu \mathrm{M}$ glutamate: $2.942 \mathrm{mg}$ of glutamate was dissolved in $10 \mathrm{~mL}$ of distilled water.

After the 64-day treatment schedule, different brain regions were dissected and homogenized in $80 \%$ doubledistilled ethanol (for every $100 \mathrm{mg}$ of the brain tissue, $2 \mathrm{~mL}$ of
$80 \%$ alcohol was used). Homogenates were transferred to polypropylene tubes and centrifuged at 1,200 rpm for 10 minutes. One milliliter of the supernatant was then transferred into small test tubes and evaporated to dryness at $70^{\circ} \mathrm{C}$ in an oven. The residue was reconstituted in $100 \mathrm{~mL}$ distilled water, and $10 \mathrm{~mL}$ was used for spotting on Whatman number 1 chromatography paper. Standard solutions of glutamate at a concentration of $2 \mathrm{mM}$ were also spotted using an Eppendorf micropipette; the spots were dried with a hair drier. The chromatograms were then stitched at the sides and placed in a chromatography chamber containing butanol:acetic acid:water (65:15:25, V/V) as solvent. When the solvent front reached the top of the papers, the papers were removed and dried. A second run was performed similarly, after which the papers were dried, sprayed with ninhydrin $(0.25 \%$ in acetone with $1 \%$ pyridine), and placed in an oven at $100^{\circ} \mathrm{C}$ for 4 minutes. The portions that carried glutamate corresponding with the standard were cut and eluted with $0.005 \%$ CuSO4 in $75 \%$ ethanol. Their absorbance was read against a blank in an LKB 4050 spectrophotometer at $515 \mathrm{~nm}$, and the levels were expressed as $\mu$ moles per gram wet weight tissue. ${ }^{21}$

\section{Calculations}

Glutamate levels = Unknown OD * Standard $(3 \mathrm{mg}) * 100 /$ Standard OD * Volume spotted $(10 \mu \mathrm{L})^{*} \mathrm{X}$

where $\mathrm{A}$ is amino acid content in $\mu$ moles per gram wet weight tissue, 100 is conversion factor for gram wet weight tissue, and $\mathrm{X}$ is weight of the tissue in gram.

\section{Histopathology}

Mixing Cresyl Violet for $300 \mathrm{~mL}$ Staining Wells

Cresyl violet stock solution: 0.2 g cresyl violet-acetate was mixed with a stir bar in $150 \mathrm{~mL}$ distilled water for 20 minutes. 
Buffer solution pH 3.5: $282 \mathrm{~mL}$ of $0.1 \mathrm{M}$ acetic acid ( $6 \mathrm{~mL}$ of concentrated acetic acid per $1,000 \mathrm{~mL}$ distilled water) was added to $18 \mathrm{~mL}$ of $0.1 \mathrm{M}$ sodium acetate $(13.6 \mathrm{~g}$ in $1,000 \mathrm{~mL}$ distilled water). Finally, $30 \mathrm{~mL}$ of cresyl violet stock solution was added to $300 \mathrm{~mL}$ of buffer and mixed for 30 minutes.

\section{Staining Procedure for Frozen Sections}

The well containing stain was placed in an oven or incubator for at least 1 hour at $60^{\circ} \mathrm{C}$ prior to staining. Sectioned tissues were mounted on slides that were loaded on to holders 20 minutes before staining to stabilize to room temperature. The holder was then placed into the wells containing the following solutions for the time indicated.

Xylene (5 minutes), 95\% alcohol (3 minutes), 70\% alcohol ( 3 minutes), deionized distilled water ( 3 minutes), cresyl violet acetate ( 8 minutes) at $60^{\circ} \mathrm{C}$ (oven), distilled water (3 minutes), 70\% alcohol (3 minutes), 95\% alcohol (1-2 minutes), and $100 \%$ alcohol (up to 10 dips to remove any streaks; one dip if no streaks were found). Care was taken not to remove all the stain. Xylene (5 minutes) was placed in next xylene well, and lid was kept closed. The slides were allowed to stay in the well until cover slipped (up to 24 hours) using a xylene-based mounting media and top-grade coverslips. For fewest air bubbles and best long-term slide storage, the slides were placed for a combined total of at least 30 minutes in xylene. ${ }^{22,23}$

\section{Total Neuronal Number}

The total neuronal number of subregions of CA1 and CA3 regions of the hippocampus was estimated by using the method of optical fractionator described by West et al. ${ }^{24}$

\section{Data and Statistical Analysis}

The values are expressed as mean $\pm \operatorname{SEM}, n=6$, analyzed by one- and two-way analysis of variance (ANOVA) followed by Tukey's post hoc test in which $p \leq 0.05$ was considered significant. Graph pad prism version 6 was used for statistical analysis.

\section{Results}

\section{Antiepileptic Activity}

Fig. 1 and - Table 3 illustrate convulsive scores based on Racine's scale for seizures. A lessened convulsive score was

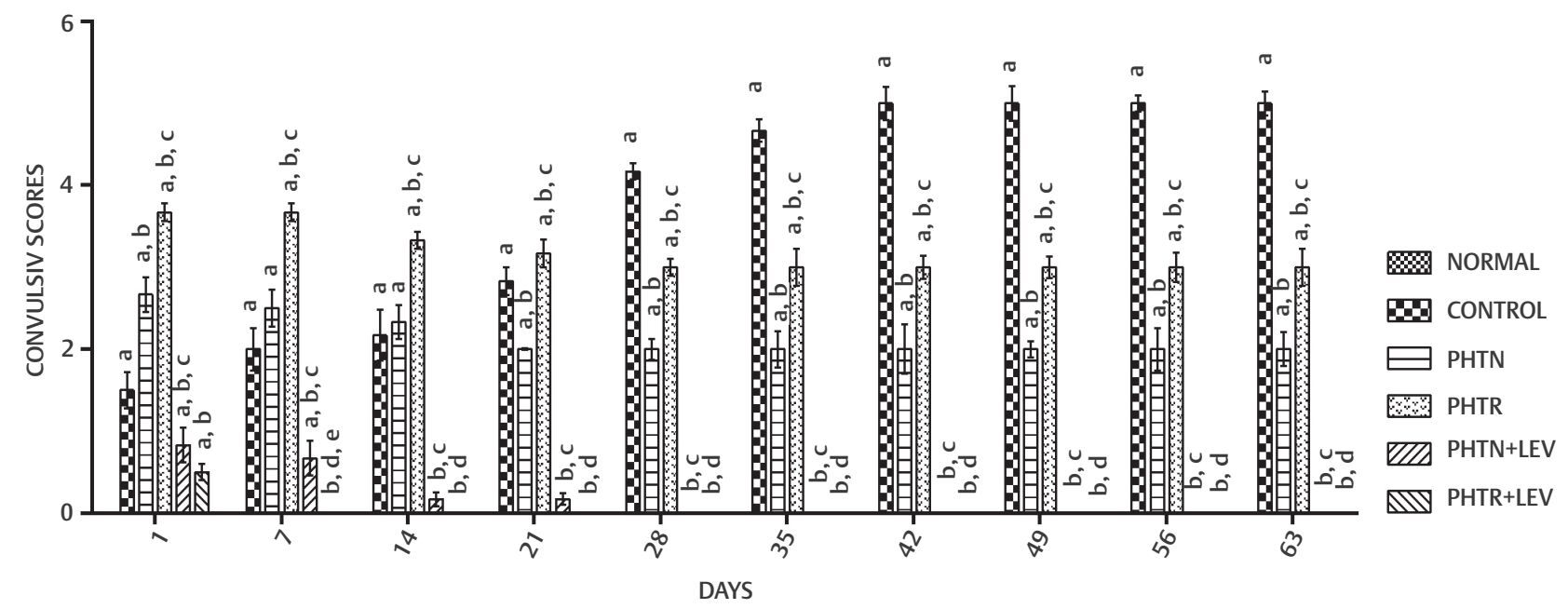

Fig. 1 Antiepileptic activity of phenytoin normal dose (PHTN) and phenytoin reduced dose (PHTR) alone and in combination with levetiracetam (LEV). Values are mean \pm SEM, $n=6, p \leq 0.05$ analyzed by two-way ANOVA followed by Tukey's post hoc test. (a) Significant when compared with normal. (b) Significant when compared with control. (c) Significant when compared with PHTN, (d) Significant when compared with PHTR. (e) Significant when compared with PHTN + LEV.

Table 3 Antiepileptic activity of normal and reduced doses of PHT both alone and in combination with LEV (percentage protection)

\begin{tabular}{|l|l|l|l|l|}
\hline \multirow{2}{*}{ Day } & PHTN & PHTR & PHTN + LEV & PHTR + LEV \\
\cline { 2 - 5 } & \multicolumn{3}{|c|}{ \% protection compared with control } \\
\hline 63 & 60.0 & 40.0 & 100.0 & 100.0 \\
\hline
\end{tabular}

Abbreviations: LEV, levetiracetam; PHT, phenytoin; PHTN, phenytoin normal dose; PHTR, phenytoin reduced dose. 
seen in both PHTN $(2.00 \pm 0.21 ; p \leq 0.05)$ and PHTR $(3.00 \pm$ $0.27 ; p \leq 0.05$ ) than the control group having a convulsive score of $5.00 \pm 0.15$. Addition of LEV for groups of both PHT (i.e., PHTN + LEV and PHTR + LEV) further reduced the convulsive scores to $0.00 \pm 0.00 ; p \leq 0.05$ and $0.00 \pm 0.00 ; p \leq$ 0.05 , respectively. - Fig. 2 shows the percentage mortality of mice for the study period of 64 days where the results of control or pilocarpine-treated group were found to be 20.00 $\pm 0.24 ; p \leq 0.05$.

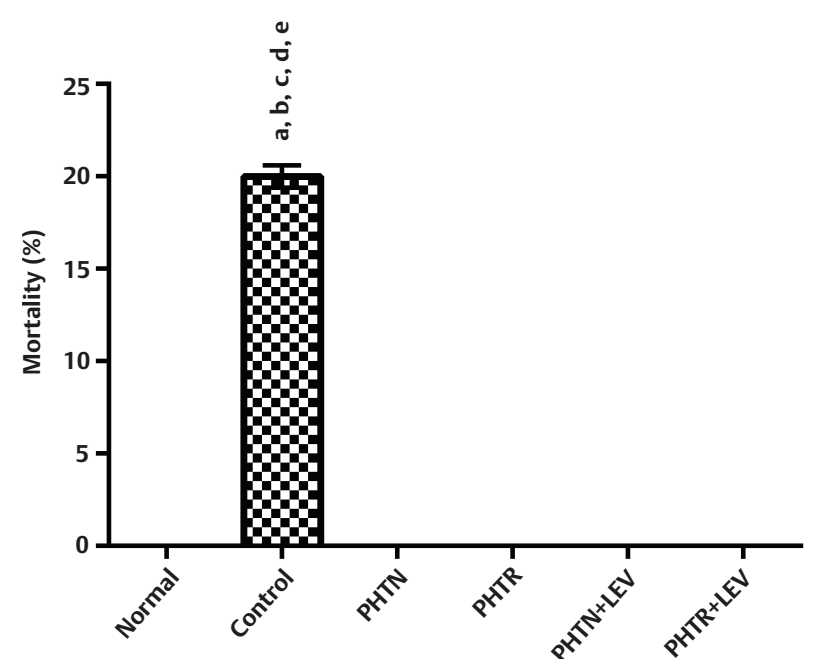

Fig. 2 Percentage mortality. Values are mean \pm SEM, $n=6, p \leq 0.05$ analyzed by one-way ANOVA followed by Tukey's post hoc test. (a) Significant when compared with normal. (b) Significant when compared with phenytoin normal dose (PHTN). (c) Significant when compared with phenytoin reduced dose (PHTR). (d) Significant when compared with PHTN + LEV (levetiracetam). (e) Significant when compared with PHTR + LEV.

\section{Memory Impairment Activity}

-Fig. 3 denotes error scores obtained from RAM, where the control group increased the same after a study period of 64 days by $21.20 \pm 0.20 ; p \leq 0.05$ than the normal group $(0.00 \pm$ $0.00)$. A similar increase in the errors was detected in PHTN group by $35.50 \pm 0.56 ; p \leq 0.05$, which was found to be more than that of control. Out of these, noticeable measurement of errors was revealed in the reduced dose of PHT, that is, in PHTR $(28.50 \pm 1.03 ; p \leq 0.05)$, which was found to be less than that of PHTN. When looking at the combination groups involving LEV, there was an extreme decline in error scores in groups PHTN $+\operatorname{LEV}(1.33 \pm 0.33 ; p \leq 0.05$ compared with control and PHTN) and PHTR + $\operatorname{LEV~}(1.00 \pm 0.17 ; p \leq 0.05$ compared with PHTR).

\section{Acetylcholinesterase Levels}

- Fig. 4 represents AChE levels, in which the control group ( $7.52 \pm 0.71 ; p \leq 0.05 \mu \mathrm{moles} / \mathrm{mg}$ protein) increased the enzyme levels than the normal ( $2.84 \pm 0.48 \mu$ moles $/ \mathrm{mg}$ protein $)$. An intensified escalation of the same was found in cases of PHTN (15.78 $\pm 0.86 ; p \leq 0.05 \mu$ moles $/ \mathrm{mg}$ protein) and PHTR (10.48 $\pm 0.50 ; p \leq 0.05 \mu \mathrm{moles} / \mathrm{mg}$ protein) than the control. However, a reduction in the above enzyme rise was brought about in groups of PHTN + LEV $(6.58 \pm 0.94 ; p \leq 0.05 \mu$ moles/mg protein $)$ and PHTR + LEV (5.17 $\pm 0.87 ; p \leq 0.05 \mu$ moles/mg protein $)$.

\section{Glutamate Levels}

- Fig. 5 is an indication of brain glutamate measures. These levels were found to increase in the control $(8.23 \pm 0.40$; $p \leq 0.05 \mu \mathrm{moles} / \mathrm{mg}$ wet weight tissue) compared with the normal of $2.07 \pm 0.31 \mu \mathrm{moles} / \mathrm{mg}$ wet weight tissue. Both sets of treatment groups of PHTN and PHTR witnessed an increment in levels of glutamate (15.78 \pm 0.91 and $12.78 \pm 0.83$; $p \leq 0.05 \mu \mathrm{moles} / \mathrm{mg}$ wet weight tissue), respectively, compared

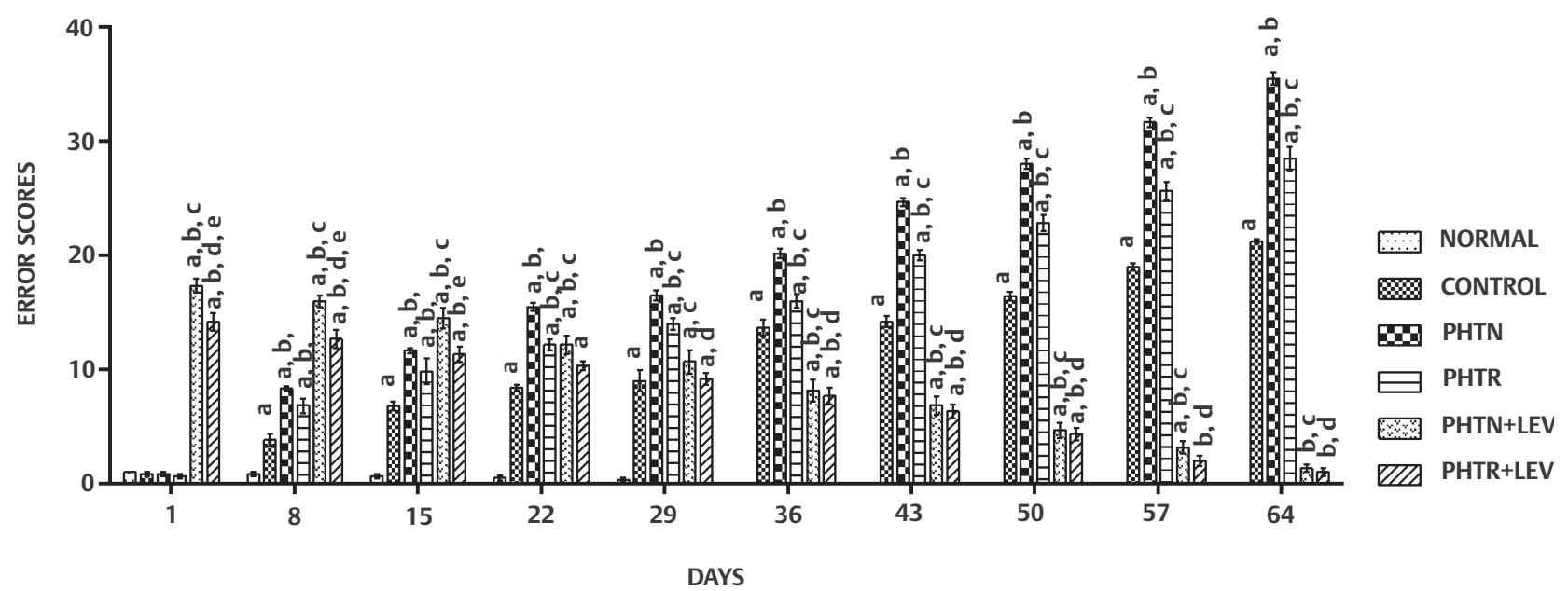

Fig. 3 Memory impairment activity of phenytoin normal dose (PHTN) and phenytoin reduced dose (PHTR) alone and in combination with levetiracetam (LEV). Values are mean \pm SEM, $n=6, p \leq 0.05$ analyzed by two-way ANOVA followed by Tukey's post hoc test. (a) Significant when compared with normal. (b) Significant when compared with control. (c) Significant when compared with PHTN. (d) Significant when compared with PHTR. (e) Significant when compared with PHTN + LEV. 


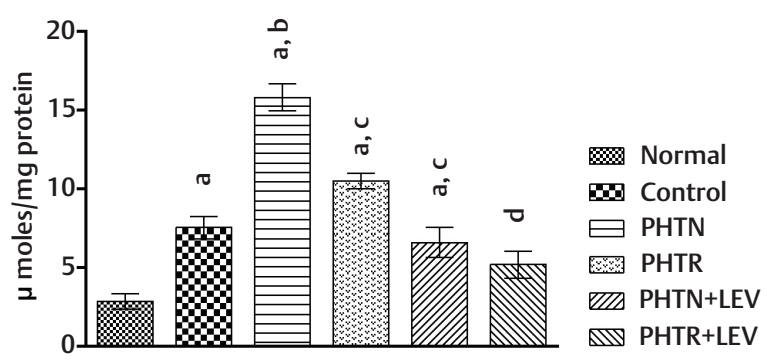

Fig. 4 Brain AChE levels. Values are mean \pm SEM, $n=6, p \leq 0.05$ analyzed by one-way ANOVA followed by Tukey's Post Hoc test. (a) Significant when compared with normal. (b) Significant when compared with control. (c) Significant when compared with PHTN. (d) Significant when compared with PHTR.

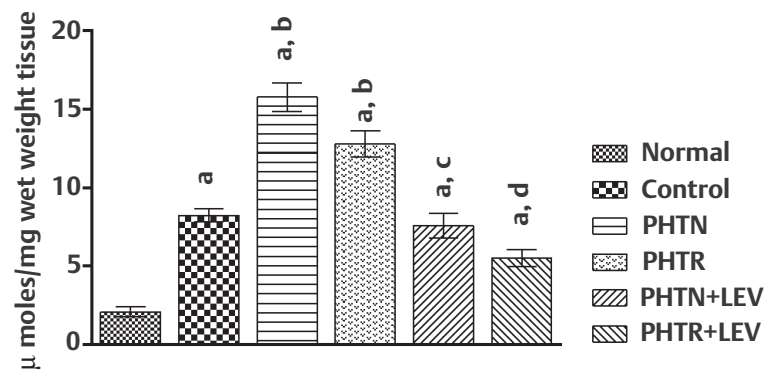

Fig. 5 Brain glutamate levels. Values are mean \pm SEM, $n=6, p \leq 0.05$ analyzed by one-way ANOVA followed by Tukey's Post Hoc test. (a) Significant when compared with normal. (b) Significant when compared with control. (c) Significant when compared with phenytoin normal dose (PHTN). (d) Significant when compared with phenytoin reduced dose (PHTR).
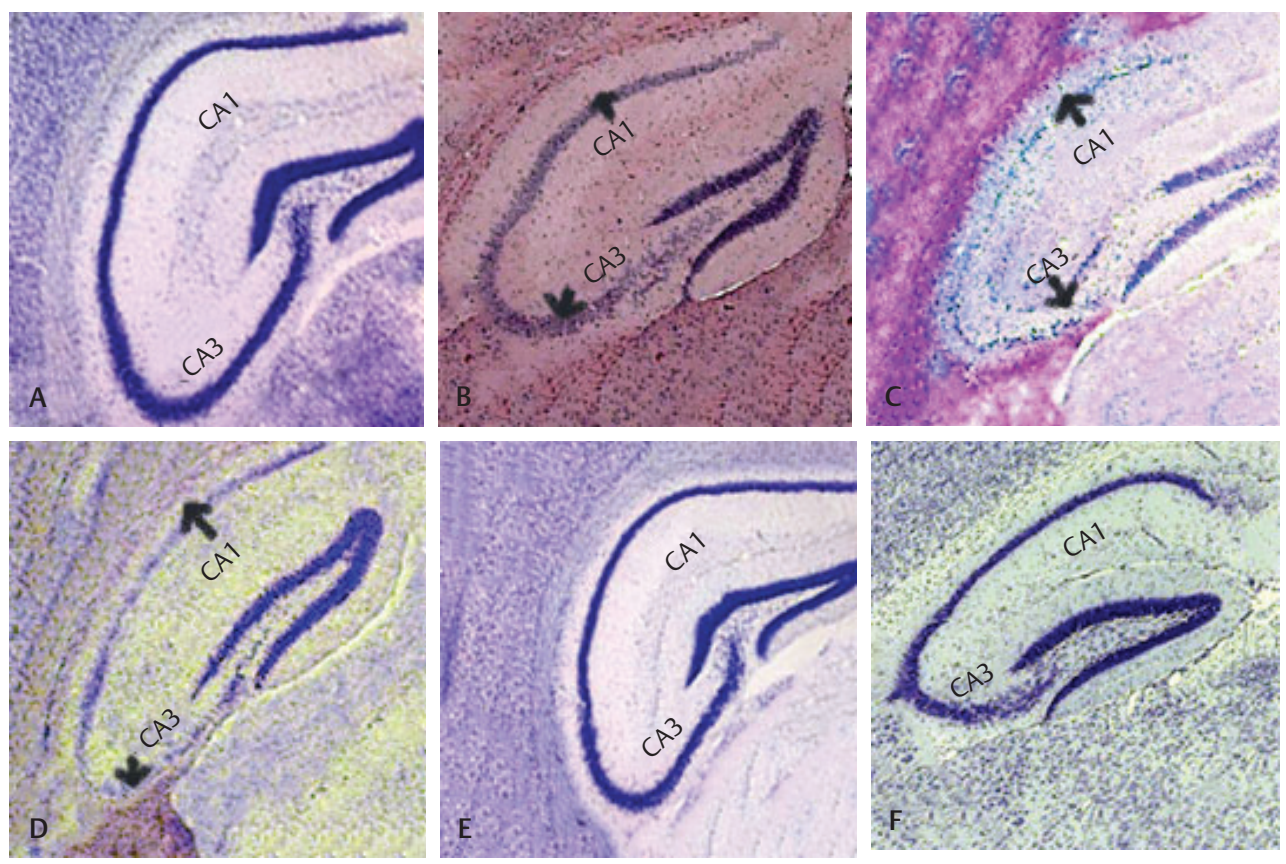

Fig. 6 Nissl staining of the hippocampus. (a) Normal group showing no disruption in CA1 and CA3 regions. (b) Control group showing significant destruction of regions of CA1 and CA3 regions. (c, d) Worsening of the hippocampal regions when PHT was administered at normal and reduced doses. $(\mathbf{e}, \mathbf{f})$ Correction by combination LEV with PHTN and PHTR exhibiting no destruction in regions of the hippocampus involved in memory (magnification 10X, scale bar $0.25 \mathrm{~mm})$.

with that of normal and control groups. In treatment groups of PHTN + LEV $(7.58 \pm 0.79 ; p \leq 0.05 \mu$ moles/mg wet weight tissue) and PHTR + LEV (5.51 $\pm 0.53 ; p \leq 0.05 \mu$ moles/mg wet weight tissue), a decrease in the levels of the excitatory amino acid were detected than control, PHTN, and PHTR groups.

\section{Histopathology}

The neurodegeneration process in areas of CA1 and CA3 (subregions of the hippocampus mainly involved in memory processes) upon cresyl violet staining has been explained in -Fig. 6. Apart from this, a quantitative method called the optical fractionator was used to estimate the number of neurons in regions of CA1 and CA3 as shown and described in - Fig. 7. It was found that PHTN reduced the total number of neurons by CA1: 45,521 $\pm 5,350$ and CA3: 49,763 \pm 7,701; $p \leq 0.05$ when compared with control (CA1: 89,564 $\pm 8,314$ and CA3: 99,280 $\pm 4552 ; p \leq 0.05$ ) and normal (CA1: 164,350 $\pm 13,917$ and CA3: $179,460 \pm 17,205 ; p \leq 0.05$ ) groups. However, the reduction was less in case of PHTR (CA1: 49,051 \pm 5,840 and CA3: $56,504 \pm 4,722 ; p \leq 0.05$ ). In cases of PHTN (CA1: 143,933 $\pm 13,172$ and CA3: $167,098 \pm 12,518.9 ; p \leq 0.05$ ) and PHTR (CA1: 157, $769 \pm 13,441$ and CA3: $177,337 \pm 11,332$; $p \leq 0.05$ ) in combination with LEV, the extent of reduction in total neuronal number was very much less when compared with control, PHTN, and PHTR groups.

\section{Discussion}

Epilepsy and MI go hand in hand, and this adverse effect tends to worsen upon AED administration. The hypothesis of 


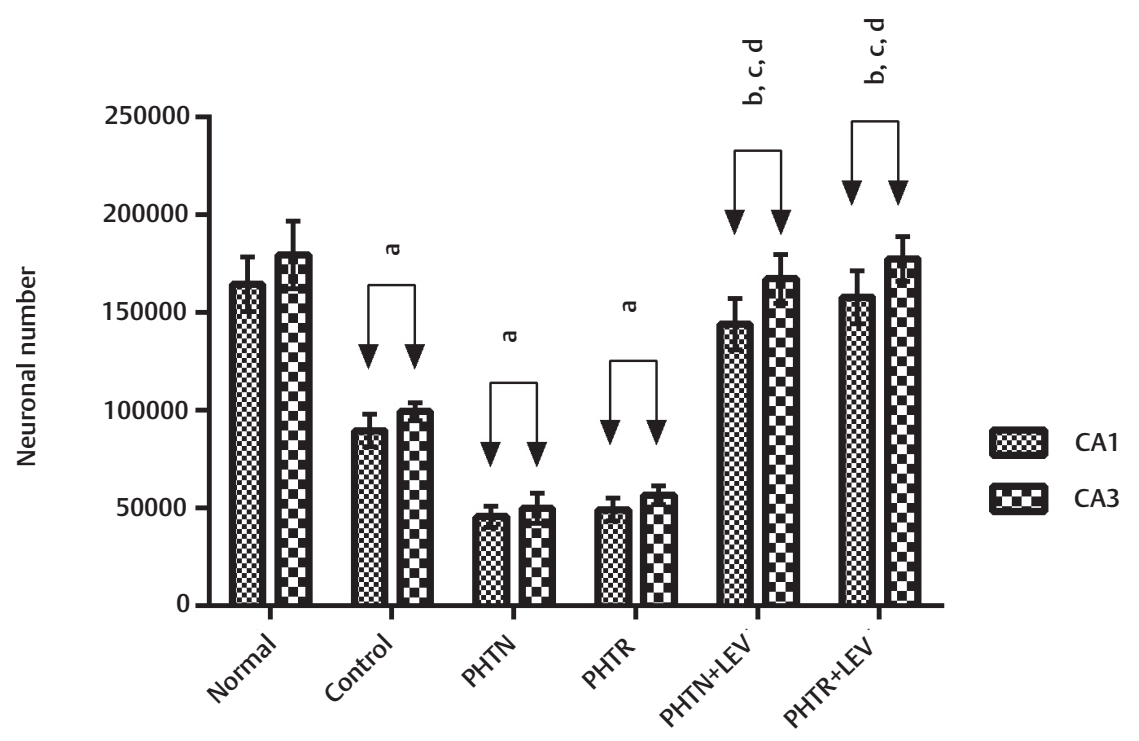

Fig. 7 Total neuronal number of CA1 and CA3 regions of the hippocampus. Values are mean \pm SEM, $n=6, p \leq 0.05$ analyzed by two-way ANOVA followed by Tukey's Post Hoc test. (a) Significant when compared with normal. (b) Significant when compared with control. (c) Significant when compared with phenytoin reduced dose (PHTN). (d) Significant when compared with phenytoin reduced dose (PHTR).

this study, that is, to correct the worsening of the above said adverse effect by co-administering an antiepileptic memory enhancer, was achieved by using LEV.

\section{Antiepileptic Activity}

The pilocarpine mouse model shares many of the characteristics of human TLE. ${ }^{25}$ Interpretation of convulsive scores by pilocarpine induced SE can be described as follows: the lesser the convulsive score, the better is the AED potency. Considering - Table 3, the tactic used to obtain a lesser degree of MI, that is, by dose reduction of the AED, produced a disagreeable outcome of reduced efficacy. A significant correction by LEV, when combined with PHT, was attained along with a better antiepileptic potential than monotherapy of the AED used for treatment. This could therefore support the fact that polytherapy of LEV with an AED should be preferable than monotherapy. ${ }^{26}$

\section{Memory Impairment Activity}

Radial arm maze that was used for evaluating MI has been extensively used for the evaluation of working and reference memory. ${ }^{27}$ Here error scores from RAM and MI are in proportion to each other (i.e., increased errors are an indication of increased degree of MI and vice versa). This is the basic principle applied for interpretation of RAM observations. Increased error scores of the control group were found to be significant when compared with the normal group, thus authenticating the declaration that MI is in association with TLE. ${ }^{28} \mathrm{~A}$ substantial advancement in errors were noticed in both PHTN and PHTR than control. This substantiates the fact that an AED itself has a self-governing potential to impair memory in addition to exacerbate the condition of MI. ${ }^{29-31}$ The dose reduction of the AED, that is, in PHTR, brought about a significant decrease in magnitude of MI than PHTN, which supports the approach of lowering the degree of MI by dose reduction. Furthermore, the addition of LEV to the treatment regimen had a superior impact than the approach of reduced dose of AED through monotherapy that was a noteworthy observation when compared with the control group.

\section{Brain Acetylcholinesterase Levels}

The implication of acetylcholine to memory is not a current awareness. ${ }^{32,33}$ Both normal and reduced doses had a negative impact on memory, which was observed by a significant increase in AChE levels. The reason for this increment by PHT could be via oxidative stress that enhanced the AChE activity, thereby depleting the levels of acetylcholine in brain regions resulting in subsequent $\mathrm{MI}^{34}$

On the combination line of treatment with LEV, a significant decrease in the levels of AChE was achieved. Unlike Alzheimer's disease, TLE is not classified as a neurodegenerative disease although there are various underlying mechanisms for neurodegeneration in TLE. ${ }^{35}$ When considering AD, cholinergic deficit is one of the factors governing the disease and use of acetylcholinesterase (AchE) inhibitors for the symptomatic treatment of $\mathrm{AD}$ involved cognitive dysfunction is common. ${ }^{12}$ Additionally, LEV has been found to be beneficial in the case of $A D$ by improving the cognition deficits. Hence based on these reports and results of decrement in levels of AChE when combined with LEV, this combination molecule may possess AChE inhibitory activity. ${ }^{36}$

\section{Brain Glutamate Levels}

Although there is a link between glutamate levels and epilepsy, no strong indication of this amino acid to be proportionate to MI due to epilepsy is available. ${ }^{37}$ However, memory and glutamate concentration are unique to patients suffering from multiple sclerosis where TLE is said to be its manifestation. ${ }^{38,39}$ Therefore, cognitive impairment involving MI could be a common link found in both conditions due to glutamate. 
The neurotoxic property of glutamate, above normal levels, could be another causative factor of MI. ${ }^{40}$ Considering these evidences, LEV in combination with PHT brought about a reversal of increased glutamate levels, thereby reducing its neurotoxic profile as well as bringing about synergized effect in antiepileptic potential. This mechanism of reduction in glutamate levels by LEV may be by means of modulating presynaptic P/Q-type voltage-dependent calcium channel. ${ }^{41}$

Alteration in these brain biochemical measures were supported by hippocampal staining and estimation of total neuronal number.

\section{Conclusion}

The elucidations from this research findings link the cause of MI associated with TLE to be a result of interferences in cholinergic and glutamatergic pathways. Though the extent of MI was condensed upon dose reduction of the AED in focus (i.e., PHT), its potency as an AED was affected, which is not acceptable for disease management. This notion was, however, tackled where a nootropic (memory enhancer, LEV) furthermore holding an antiepileptic capability was introduced into the treatment regimen where this addition did not interfere with the major drug of choice for the treatment. As this study confines the conclusions to be centered on the end result of few behavioral and biochemical parameters, a supplementary and innovative research is of utmost importance.

\section{Conflict of Interest}

None.

\section{Acknowledgment}

The authors sincerely thank Dr. T. M. Pramod Kumar, Principal, JSS College of Pharmacy, Mysore, for his support and encouragement. Our gratitude also goes to the JSS Academy of Higher Education and Research, Mysore, for providing all the necessary facilities.

\section{References}

1 Ono T, Galanopoulou AS. Epilepsy and epileptic syndrome. Adv Exp Med Biol 2012;724:99-113

2 Zhao F, Kang H, You L, Rastogi P, Venkatesh D, Chandra M. Neuropsychological deficits in temporal lobe epilepsy: a comprehensive review. Ann Indian Acad Neurol 2014;17(4):374-382

3 Al-Mufti F, Claassen J. Neurocritical care: status epilepticus review. Crit Care Clin 2014;30(4):751-764

4 Eddy CM, Rickards HE, Cavanna AE. The cognitive impact of antiepileptic drugs. Ther Adv Neurol Disorder 2011;4(6):385-407

5 Löscher W, Schmidt D. Which animal models should be used in the search for new antiepileptic drugs? A proposal based on experimental and clinical considerations. Epilepsy Res 1988;2(3):145-181

6 Turski WA, Cavalheiro EA, Schwarz M, Czuczwar SJ, Kleinrok Z, Turski L. Limbic seizures produced by pilocarpine in rats: behavioural, electroencephalographic and neuropathological study. Behav Brain Res 1983;9(3):315-335

7 Goldenberg MM. Overview of drugs used for epilepsy and seizures: etiology, diagnosis, and treatment. P\&T 2010;35(7):392-415
8 Mishra A, Goel RK. Comparative behavioral and neurochemical analysis of phenytoin and valproate treatment on epilepsy induced learning and memory deficit: search for add on therapy. Metab Brain Dis 2015;30(4):951-958

9 Mondadori C, Ducret T, Borkowski J. The memory-enhancing effects of the piracetam-like nootropics are dependent on experimental parameters. Behav Brain Res 1989;33(1):79-82

10 Abou-Khalil B. Levetiracetam in the treatment of epilepsy. Neuropsychiatr Dis Treat 2008;4(3):507-523

11 Martínez-Granero MA, García-Pérez A, Montañes F. Levetiracetam as an alternative therapy for Tourette syndrome. Neuropsychiatr Dis Treat 2010;6:309-316

12 Sanchez PE, Zhu L, Verret L, et al. Levetiracetam suppresses neuronal network dysfunction and reverses synaptic and cognitive deficits in an Alzheimer's disease model. Proc Natl Acad Sci U S A 2012;109(42):E2895-E2903

13 Wright C, Downing J, Mungall D, et al. Clinical pharmacology and pharmacokinetics of levetiracetam. Front Neurol 2013;4:192

14 Ohmori H, Yamashita K, Hatta T, et al. Effects of low-dose phenytoin administered to newborn mice on developing cerebellum. Neurotoxicol Teratol 1997;19(3):205-211

15 Klitgaard $H$. Levetiracetam: the preclinical profile of a new class of antiepileptic drugs? Epilepsia 2001;42(Suppl 4):13-18

16 Furman M. Seizure initiation and propagation in the pilocarpine rat model of temporal lobe epilepsy. J Neurosci 2013;33(42):16409-16411

17 Gupta SK. Drug Screening Methods. 2nd ed. New Delhi, India: Jaypee Brothers; 2004:414

18 Vogel HG. Drug Discovery and Evaluation Pharmacological Assays. 2nd ed. Verlag Berlin Heidelberg: Springer; 2006:630

19 Ellman GL, Courtney KD, Andres V Jr, Feather-Stone RM. A new and rapid colorimetric determination of acetylcholinesterase activity. Biochem Pharmacol 1961;7:88-95

20 Rahman H, Eswaraiah MC. Simple Spectroscopic Methods for Estimating Brain Neurotransmitters, Antioxidant Enzymes of Laboratory Animals Like Mice: A Review. Hyderabad, India: PharmaTutor Art; 2008:1244

21 Raju TR, Kutty BM, Sathyaprabha TN, Shanakranarayana RS. Estimation of neurotransmitters in the brain by chromatographic methods. Brain Behav 2004;:134-141

22 Cresyl Violet Stain for Neuron Somas. Available at: http:// www.neurosciencecourses.com/cresyl-violet-stain.html. Accessed July 21, 2016

23 Deitch AD, Moses MJ. The Nissl substance of living and fixed spinal ganglion cells. II. An ultraviolet absorption study. J Biophys Biochem Cytol 1957;3(3):449-456

24 West MJ, Slomianka L, Gundersen HJ. Unbiased stereological estimation of the total number of neurons in the subdivisions of the rat hippocampus using the optical fractionator. Anat Rec 1991;231(4):482-497

25 Buckmaster PS, Haney MM. Factors affecting outcomes of pilocarpine treatment in a mouse model of temporal lobe epilepsy. Epilepsy Res 2012;102(3):153-159

26 Kaminski RM, Matagne A, Patsalos PN, Klitgaard H. Benefit of combination therapy in epilepsy: a review of the preclinical evidence with levetiracetam. Epilepsia 2009;50(3):387-397

27 Penley SC, Gaudet CM, Threlkeld SW. Use of an eight-arm radial water maze to assess working and reference memory following neonatal brain injury. J Vis Exp 2013;82(82):50940

28 McDonald CR, Ahmadi ME, Hagler DJ, et al. Diffusion tensor imaging correlates of memory and language impairments in temporal lobe epilepsy. Neurology 2008;71(23):1869-1876

29 Motamedi GK, Meador KJ. Antiepileptic drugs and memory. Epilepsy Behav 2004;5(4):435-439

30 Witt JA, Helmstaedter C. Monitoring the cognitive effects of antiepileptic pharmacotherapy-approaching the individual patient. Epilepsy Behav 2013;26(3):450-456 
31 Greener M. Beyond seizures: understanding cognitive deficits in epilepsy. Prog Neurol Psychiatry 2013;17(3):31-32

32 Hasselmo ME. The role of acetylcholine in learning and memory. Curr Opin Neurobiol 2006;16(6):710-715

33 Saraswathy GR, Maheswari E, Santhrani T. Protective effect of alpha lipoic acid against phenytoin induced behavioral abnormalities in rats. J Mol Biomark Diagn 2015;6(4):241

34 Pestana RR, Kinjo ER, Hernandes MS, Britto LR. Reactive oxygen species generated by NADPH oxidase are involved in neurodegeneration in the pilocarpine model of temporal lobe epilepsy. Neurosci Lett 2010;484(3):187-191

35 Tabet N. Acetylcholinesterase inhibitors for Alzheimer's disease: anti-inflammatories in acetylcholine clothing! Age Ageing 2006;35(4):336-338

36 Easton A, Douchamps V, Eacott M, Lever C. A specific role for septohippocampal acetylcholine in memory? Neuropsychologia 2012;50(13):3156-3168
37 Cho C-H. New mechanism for glutamate hypothesis in epilepsy. Front Cell Neurosci 2013;7:127

38 Muhlert N, Atzori M, De Vita E, et al. Memory in multiple sclerosis is linked to glutamate concentration in grey matter regions. J Neurol Neurosurg Psychiatry 2014;85(8):833-839

39 Gambardella A, Valentino P, Labate A, et al. Temporal lobe epilepsy as a unique manifestation of multiple sclerosis. Can J Neurol Sci 2003;30(3):228-232

40 McEntee WJ, Crook TH. Glutamate: its role in learning, memory, and the aging brain. Psychopharmacology (Berl) 1993;111(4):391-401

41 Lee C-Y, Chen C-C, Liou H-H. Levetiracetam inhibits glutamate transmission through presynaptic $\mathrm{P} / \mathrm{Q}$-type calcium channels on the granule cells of the dentate gyrus. $\mathrm{Br} \mathrm{J}$ Pharmacol 2009;158(7):1753-1762 